\title{
GENERAL DISGUSSION
}

THE final session of the symposium included a general discussion under the chairmanship of Dr M. F. Meier.

M. F. MEIER: I hope that this will be a session in which we achieve some degree of synthesis. We have had an excellent meeting; from my point of view it was an exciting one. It was unusual because there were so many different kinds of approaches to problems that are very interrelated. For instance, we have heard people talk about conditions at the base of vast glaciers measuring megametres in extent; others dealt with conditions at the base of glaciers measuring kilometres, or only a few hundred metres in extent, or even surfaces having no glaciers at all at the present time. We have people at this meeting who work only with a pencil and paper, others who work with computer cards, or oscilloscopes, or cations, or water pressures, or other sorts of things like that, and people who scrabble with pick and shovel. We have seen some fascinating views of the bed. Some of these views, such as in the bore-hole photographs, were only square centimetres in extent; some, such as the glacier bed seen in tunnels, measured square metres in extent; some, such as the margins of the glaciers, were a few hundreds of metres in extent; and some were beautiful views of formerly glaciated terrain of kilometres in extent. So we are looking at this picture from many different ways, at many different scales, and using many different methods of attack. One of the problems that we have noticed in the past is a separation of people who are interested in ice from those people who are interested in the effects of past ice movements. I hope that one of the things we are doing at this meeting is to bring these two schools a little closer together. The first thing I would like to do is to ask some of the glacial geologists what they have learned at this meeting from the glaciologists. What is their impression of how glacial geology might be made a more efficient science by looking at the results of the glaciologists? I would like to call Dr Dreimanis, to give his impression of the meeting so far.

A. Dreimanis: It has been very valuable for glacial geologists to have this opportunity to exchange their opinions with glaciologists and also to hear of their field and laboratory observations, and their theoretical calculations. I think that we can learn much, particularly about the conditions along and close to the glacial margin. But except for some cases where the observations by glaciologists were made further back from the ice margin, such as with deep test drillings for geophysical investigations, there still seems to be little information about what happened further back from the margin. There are several geologic features: grooves, bedrock flutings, and ice thrust forms, which are large in size and were formed subglacially. We usually do not observe them right at the ice margin of the present-day glaciers. I fully realize the logistic problems of studying these, but I would plead from the viewpoint of glacial geologists that, if possible, still more work be done further back from the ice margin. Perhaps we can discuss today what might be the possibilities of cooperation between glacial geologists and glaciologists in doing these studies.

MEIER: That is a very good point, but of course as you mention, the difficulties in observing the bed under great thicknesses of ice are considerable.

L. A. Lliboutry: I feel that we need more data on the geology and microstructure of glacial beds before we can further our knowledge of sliding and of bottom creep. There may be also debris on glaciers which could go to the bottom at some places. The unsolved problems concern the origin and incorporation of debris : is it incorporated down a crack or bergschrund or moulin, or is it plucked from the bottom? 
I. M. Whillans: I would like to say something more on the same line. I think that the glacial geologists and probably glaciologists can learn from the studies of composition of till. In particular there seems to be a conflict over the origin of till. Some workers attribute till to local origin, and others to a distant origin. Maybe tills in different places really are different. If so, that is an important result, which may bear on the actions of ice sheets in different places. There is also the question of till/moisture combination, which is important to understanding how much shearing there is at the base of the glacier transporting the till. I feel the glacial geologists should provide glaciologists with more data on these topics.

D. J. Drewry: I would like to raise a point which I think has been mentioned, but only obliquely, during the sessions. It is the effect of adding rock fragments (clasts and dispersed fines) into ice. How do they affect mechanical properties, sliding processes, basal water characteristics, and deformation of overlying layers? This area is one which has seen little work either in the laboratory or in the field and yet is probably of enormous importance in how close we approach glaciological reality. After all most glaciers and even ice sheets possess dirty, debris-charged basal horizons. Surely this is an area where substantially more effort is clearly justified.

H. F. Engelhardt: That is what we are trying to do. We try to drill holes to the very bottom of the glacier to recover such debris. In our laboratory we have many samples from the lower Io $\mathrm{m}$ or so: it is very compact debris. It is very hard to say where it all comes from; whether it is locally produced or whether it has travelled large distances. We have the impression that the ice-free debris layer at the bottom is very thin, and is probably derived very locally. It will take a lot of work to analyse this debris.

MEIER: What are we specifically going to do? The presence of debris in ice must affect the properties of the ice, and therefore must affect the deformation and the erosion and deposition at the interface.

Engelhardt: Yes. We have enormous deviation from the normal properties of ice. The usual parameters $A$ and $n$ cannot be applied, but by measuring contraction-rates and deformation-rates we can probably say more about mechanical properties of these debris-laden ice layers. We are presently working on that.

MEIER: I see, so you are not quite ready to say what the flow law of ice should be considered to be in the presence of debris.

H. Röthlisberger: There is one possible mechanism for bringing debris into the glacier which I did not have time to show yesterday, though it has been the cause of some major difficulties in our drilling operations. Below the ice fall of Glacier du Brenay we have come across sand and gravel beds within the ice at depths well above the glacier bed. We believe that these sediments were brought in by a subglacial waterfall. If I said yesterday that the channels in my opinion stay at the bed or on the slope of the valley, then this was not without reservation. When you have sediments in subglacial channels, the latter are likely to become clogged up; consequently the water may cut sideways into the ice, or in front of a waterfall it may angle into the ice to some distance and carry and deposit sediments in there. Such situations could probably best be studied by structural field geologists who could map and analyse the outcrops of this type of sediment near the terminus. I am particularly thinking of the type of work Dr Hambrey did while he was in Zürich. Although structural methods apply primarily to the interior of the ice masses, additional information on the bed condition can be expected from such studies. These methods should also eventually be tried beside all the others that we enjoyed hearing about during this symposium. 
N. W. Riley: At Newcastle we have been doing work on glacial wear. We have one interesting result, in that we have modelled wear by imagining that we only have, at the bottom of a glacier, a rock/rock contact or a clean ice/rock contact. We have set up those two extremes in the laboratory, with such contact points moving at what I consider subglacial speedsaround the region of $20 \mathrm{~m} /$ year. The interesting comparison here has been between these results and those results produced by G. S. Boulton, from under Glacier d'Argentière and Icelandic glaciers. He cemented-in tablets of rock and thereby was able to measure lowering rates. We find that if we compare our rock/rock wear experiments, with no ice present, no water present at all, that we get very similar results to the actual wear which Boulton has measured underneath the glacier. So there is no ice at all! It is a rock/rock contact for which we get pretty close comparison. On the structural geological side of this we are looking into the way in which fragments may be brought from the bed. As one would imagine, the cracks have to be propagated through a matrix in order for large particles to be removed from the bed. We are examining whether there is any kind of correlation between the wear coefficients that we measure for the rock/rock contact, and the energy required to propagate cracks through a rock matrix. This is proving pretty tricky, there is very little published to my knowledge concerning crack propagation energies for rocks. The only reference I know is to a granite, this is from some South African work. The ratio of the crack propagation in ice, as the thing that might be doing the damage, and the crack propagation in a granite, were ice moving over that granite, is about Ioo to I. Thus, in a granite we need Ioo times as much energy to propagate the crack as you would to propagate the crack through ice. I have been working with sandstone which would certainly require less than granite, but how much less I am not really sure.

MEIER: That brings us back to the paper by Kamb and others, pointing out the role of rock friction at the base of the ice.

C. F. RAymond: We see two opposite views of the bottom of a glacier; one in which the ice is fairly clean and makes a rather sharp contact with solid rock, and the other where it is choked with debris. But drilling holes down to the bottom of glaciers and sampling on twoinch $(5 \mathrm{~cm})$ diameter patches, here and there, is a dismal prospect when you realize the work in drilling these holes. I would like to direct a question back to the people who look at exposed glacial beds, whether they be geologists or glaciologists. The question is whether features of those beds might be used to get some idea of just what is characteristic, if anything is characteristic, or what variety of conditions we might expect from various locations. Are there characteristics of the erosion marks or deposits which possibly might enable one to distinguish between basal conditions of dispersed particles in relatively clean ice or debrisladen ice? There has been some suggestions of that I think in some of the papers.

Dreimanis: Just replying to the last question, I may mention that some detailed work has been done by glacial geologists on structures, and also lithology, at the base of tills. I would like also to make a plea to glacial geologists not just to look at till as a massive deposit without any structures, because by brushing and washing with a water jet, you can expose such a great variety of structures which can provide us with very valuable additional information. This has been done, but still not sufficiently. At the same time may I use the opportunity also to refer to Ian Whillans' plea that glacial geologists do more provenance studies and provide more analyses of provenance. Several have been done during the last decades, and numerous analyses have been published in scattered reports, but still at least ten times more analyses are in files, as the journals do not like long papers. The government and other institutions cannot publish long, thick memoirs any more. Because of that, the INQUA Commission on genesis and lithology of Quaternary deposits has established a working group under Ron May. The group will try to propose some computer processing and distribution of this 
information. Some of the other working groups of the INQUA Commission have examined analytical methods. A paper was published recently in Fournal of Sedimentary Petrology on the various methods used. I believe that we should standardize some of our methods and presentations, at least the particle sizes of various analyses, so that we could compare results of different authors. We still have a long way to go to make the data comparable; although there is an enormous amount of data on till characteristics which is already available.

MeIER: Generalizing from this huge amount of data certainly is a problem.

RILEY: I would like to answer the question from Dr Raymond. I said that the comparison between the erosion-rates that we have measured and those produced by Boulton was extremely good. As far as I know Boulton's work is the only work where we have actually had wear measured in situ. We have certainly heard from Gunnar Østrem over a number of years concerning sediments transported from Norwegian glaciers from which we have inferred rock surface lowering rates. The ratio of experimental wear-rate to averaged field rate is about ten, so one could interpret this as saying that one only requires one-tenth of the glacial basin area to have rock/rock contacts in order that we can produce the amount of material measured.

B. Hallet: I would also like to come back to Dr Raymond's point. Glacial geologists could study the debris cover of recently deglaciated glacier beds to obtain information on the abundance of debris formerly present within or at the base of retreating glaciers. It seems to me that if one sees a vast expanse of glaciated bedrock with little debris, perhaps bordered by a distinct moraine, and if one can establish that much of the material was not removed by proglacial streams, the former debris load in and on the glacier must have been very low. On the other hand, if one observes a thick accumulation of debris being exposed by glacial retreat, the debris content of that glacier must have been relatively high. Hence, studies of recent glacial sediments on proglacial areas in different terrains could yield valuable information on the abundance of debris within, on top of, and at the base of glaciers and could help us understand the factors controlling the debris content of glaciers.

R. C. Metcalf: I had three points I wanted to make. The first is that in my own research one finds quite a bit of information on fracture energy in rock associated with industrial grinding and mining-engineering grinding work. The second point is that getting back to the work of Dr Goldthwait and Ian Whillans dealing with the megaripples and sine ripples of Kelleys Island, one of the things that struck me was the inference that these formed under deep ice associated with continental ice sheets. Yet what was very striking to me, and perhaps to some of you, was Barclay Kamb's slide of the terminus of Blue Glacier. You appear to see exactly the same forms; three apparent megaripples associated with the three terminus streams. Furthermore, we see the sine ripples associated with each of the megaripples, and we see the smaller ripples superposed on the sine ripples. Now the vegetation cover and the weathering of the surfaces indicates that this bedrock has been exposed only since the neoglacial advance. So they did not form under a continental ice sheet. I suggest that it does not necessarily have to be a continental ice sheet for those ripples to form. My final point is that I was curious whether Mr Riley's group had looked at the energy expended in their wear experiments to provide a comparison with the attritivity values that Kamb talked about.

Riley: In answer to the final point, yes we have. However, I do not find it useful to quote wear as geographers and glaciologists would normally quote it. We normally say the surface has been lowered a given distance over a given time. I find it much more useful to express wear the way it is expressed in engineering, that is as the volume of material removed per unit force per unit distance; which in fact gives the measure that I have just been asked for. I can communicate that later, but I would recommend anyone else who examines wear to use that as a parameter of wear. 
RöTHLISBERGER: I would like to point out that while there is some scarcity of direct observation of abrasion in the field, it is not completely absent. During the 1920 glacier advance in Switzerland, holes were drilled in some rock knobs in front of advancing glaciers and the amount of abrasion and plucking was then measured after the glacier had retreated again. This was done in front of the upper Grindelwaldgletscher and in front of Allalingletscher by Lütschg. May I emphasize that now seems to be the time to do similar work, as Alpine glaciers have started to advance again. I am ashamed to admit that we have not done much ourselves except in a single case in 1964 where we have surveyed and prepared for later resurveying a small area of a rock knob in front of Glacier de Trient, a glacier which has since advanced some $300 \mathrm{~m}$. Now we do not know when it is going to retreat again. It may not look a very promising endeavour, not knowing if one will live long enough to get any results, but efforts in this direction should nevertheless be made without delay, possibly using new techniques.

May I continue with another question addressed to Dr Boulton? I was astonished by his remark that he thinks the ratio of plucking to abrasion would be very large; that there would be much more plucking than abrasion. I have always thought that the reverse was the case, on the basis of two things; one is the observation that a much larger amount of small particles than coarse ones is carried in glacial streams. The other is that if one visualizes a plucked stone of the same material as the underlying material, the underlying material being jointed rock, then one would expect that the plucked stone would be able to break off one or more pieces of the bedrock before becoming completely fragmented. The next step would be the formation of striations and such processes. Small rock particles will break out from the tool and the bedrock alike. Finally, there are the mineral grains, say quartz grains; they will grind and I would expect that the grinding effect would be equal on the grains which move and on the grains of the rock below. All this indicates that a multiplying effect in abrasion to the original plucking has to be expected. I am aware that the abrasive effect on the bed will be less where the stones in the basal ice layer rub against each other, but I still wonder if $\mathrm{Dr}$ Boulton's statement, that plucking is more important than abrasion, is generally correct.

G. S. Boulton: What I said was hedged around with restrictions. The first one was the assumption that there are two processes going on, one of which could be called abrasion, or rubbing by a tool, which produces fine material from break-down both of the bed and of the tool, and the other one is plucking, by which the tool is produced. Of course in valley glaciers, many large blocks are derived from disintegration of flanking mouhtain walls. Rocks from this source fall onto the glacier margin, which is a basal flow line, and may thus subsequently travel immediately above the bed and abrade it. Obviously in valley glaciers where such a process is important, the statement I made about the relative importance of plucking and abrasion does not necessarily apply. It applies primarily to the case of an ice cap or an ice sheet moving over a rock bed. My logic is that, if it is true that most of the rock flour is produced because of movement of large particles over the bed, and if we assume that these large particles and the bed have a similar lithology and thus similar hardness, then we would expect the rate of loss on both surfaces to be similar. Thus most of the fines in tills are produced because of abrasion between large particles and the bed. In the resultant tills we find many large particles, representing tools which have survived, and thus plucking must be volumetrically more important than abrasion where there is no supraglacial debris source.

RöTHLISBERGER: I have often wondered why the surviving tools in relation to the fines have not been studied more thoroughly in a place where this can be done in a particular case, namely at the junction of two large tributary glaciers. As the two ice bodies join to form a single tongue, at least if there is some bed slip, basal till from the tributaries is dragged along at the interface between the two ice masses, forming an internal medial moraine. Now what one sees on the surface consists only of the large particles and not the fine material, but if you 
look in crevasses cutting across the medial moraine, or by digging, you will find also some fine material. I have to admit that far less fine than coarse material seems to be present. However, often the coarse material has never touched the bed, if it originates from rock falls onto the firn; such rocks are carried along in the ice. A few rounded stones and boulders showing striations will nevertheless be found beside the angular rocks. They represent the tools which have acted at the bed of one of the other tributary glacier above the junction. That type of coarse material only should be compared with the layer of fines embedded in the ice. From tentative visual observations of crevasse faces I expect that the volume of fines and coarse tools are probably of the same order of magnitude in some typical cases of Alpine valley glaciers. Since an unknown fraction of the abrasion flour will have been washed away by subglacial drainage water before the internal moraine is formed, a lower limit only of the amount of fines could be determined by a quantitative study of the inclusions in the ice. I nevertheless think that such a study would be worth trying.

W. E. S. HeNoch: I am interested in the features that are produced by glaciers, both erosional and depositional, such as crescentic scars, lunate fractures, giant grooves, and drumlins. I do not believe that we will know how glaciers behave until we simulate the formation of these features. Would it be possible to devise an experiment to give us some indication how plucking is achieved?

I have not heard if there are any experiments undertaken to simulate the changes of pressure and temperature and pore pressure. The last two factors appear to be important in the formation of giant scars (crescentic gouges, lunate fractures) and also in the formation of drumlins. We know how glacier ice will deform under pressure, but can an experiment be devised where the ice will be forced to flow and give some indication how giant grooves are produced? Features like giant grooves and crescentic scars cannot be produced by friction or impact of rock on rock or metal on rock. They are peculiar to glacier action and are such beautiful forms. We must not be satisfied till some experiments are undertaken to simulate the formation of these features.

Lliboutry: I would like to suggest a process for grinding or plucking which involves the repetition of very strong stresses, when a rock which moves at the bottom of the glacier pushes against the bedrock. Since there are fluctuations in the water pressure and also in the movement of basal ice, one moment there may be a very high normal pressure on a localized point, and next moment nothing. I see this working like the cogged wheels of rock drills, where only the repetition of the pressure of the cogs makes the rock shatter.

R. A. Vivian: I would like to express my opinion on this problem of the ratio between abrasion and plucking. I agree with Hans Röthlisberger's opinion: I think that abrasion is much more important under a thick temperate glacier than plucking, but maybe this opinion is too general. One must quantify it and the quantification would be a ratio which would depend on the character of the rock underneath. For this it is necessary to study the geology of the bedrock. The ratio would also depend on the place where you are under the glacier. It would certainly be very different in the central part of the glacier and out on the margin of the glacier, where it is possible to measure large differences of temperature near and below $0^{\circ} \mathrm{C}$. Another point concerns the comment by Rayrnond. I think that it would be interesting to calculate the percentage of different types of interface under glaciers. We have a good opportunity for this in the world inventory of glaciers. From a theoretical point of view it would be interesting to know the relative proportion of temperate or cold basal ice under glaciers, not just at one point, or one area under a glacier, but all over.

Boulton: I wish to take up something that Professor Lliboutry said about the possible processes by which plucking might occur, and it is also relevant to Robert Vivian's statement. One should not think that we know nothing about the plucking process. There are many 
observations under glaciers and beyond glaciers which enable us to identify the plucking processes which have occurred. The difficult problem is to generalize from there to say how representative of all the processes that might produce plucking these observations are. Of course the number of observations that we can make is very small and therefore the chance of being able to make a representative statement is equally small. I suggest that we need more studies such as those of Matthes in which old glacier beds which are very extensively exposed are examined in detail. One can then make general statements about the forms of glacier beds, and the clear way would be to model the processes so as to be able to reproduce the glacier beds. A major problem lies in our current state of knowledge of the forces at the base of glaciers. We simply do not have theories which are capable of producing predictions of the ways in which pressures and shear forces ought to vary over a realistic bed and it is extremely difficult to establish this empirically. So before we can go on to assess how general some of the processes which have been observed are, we need to improve theories of basal movement.

R. P. Goldthwart: I'd like to remind everyone of two rather old experiments. One is the work of Dick Jahns on the Chelmsford granite a number of years ago. He could identify the characteristics of sheet jointing from similar granites outside the glaciated area, and thereby calculate the depth of glacial erosion in that particular knob of granite in Massachusetts. With these calculations he could show for that example that the plucking under the continental ice there amounted to ten times as much as the abrasion, during the whole glaciation. Secondly, I would like to remind us of the study which Lon Drake did on the rocks of central New Hampshire. The ice was over them, working on them, for several thousands of years, certainly. The outlines of the bedrocks are so well known that he could calculate accurately from the till what had happened to the pebbles en route from each source. Drake made a careful study of the broken surfaces versus the abraded surfaces. He found that from the original rough shapes, which you can reproduce with hammers, the rate of rounding is a very rapid process. A rounding to roundness of 6 (on the scale of 10 ) can happen at least three times in every kilometre for individual pieces. Apparently, this was at the bottom, for it was basal till. Also, the number of times of breaking en route for individual pebbles averaged at least four times per kilometre. I think we need more studies of this sort in order to get at the question of attrition.

Meier: Thank you, I think this discussion is pointing up very nicely that only the glacial geologists can tell the glaciologist what the general ratios of erosion/deposition or abrasion/ plucking are, and that only the glaciologist can tell the glacial geologist what the actual processes at the bed are.

T. J. Kemmis: I would just like to comment from a glacial (or Quaternary) geologist's point-ofview. I am working with the Quaternary glacial deposits along the southern margin of the Laurentide ice sheet. We see that quite a wide variety of processes have occurred, and we would like to reconstruct the glacial conditions in order to give us a better understanding of the landforms and the materials which comprise them. At this meeting we have seen a number of very specific studies on particular processes without an integration of what controls the occurrence of these processes. This makes it very difficult for us to assimilate how each of these studies fit into the big picture: what controls the individual processes and where they can or cannot occur?

E. M. MORRIs: Concerning that problem, glaciologists cannot really begin to give you answers. It seems to me that one of the crucial things to come out of this conference has been that we reaily do not understand one of the basic processes which we think is going on. That is why I think that Gordon Robin's work on regelation has been perhaps the most important recent 
idea. It has shown us that we need to go back to the sliding theories, to the theories of erosion and deposition, and really do them properly, and advance the experimental evidence that we have got.

RAYMOND: I would just like to comment on something that Dr Boulton said when he asked for improvements in theory in order to know something about the forces along the bottom of a glacier. I would just like to suggest that perhaps the forces and force variations are the things which are best known. They are determined largely by statics: you have to keep the ice from sliding off downhill, and so from this you can conclude something about the force variations along a locally slippery bumpy bed. What the ice is going to do in terms of freezing and melting processes and deformation is the hard part, and that of course is much less well known.

W. H. Mathews: I would like to beat the drum here a little bit for glacier hydrology, which has been to a large extent omitted in the discussion to date. I can recall finding, for example, about half a kilometre below the firn line of one glacier, beautifully rounded pebbles sitting in the glacial stream on the ice surface. I have no doubt that in this particular case it was not glacier transportation that rounded the rocks but rather water transportation. And further to Dr Röthlisberger's remarks, one of my graduate students, John Clague, working in the Rocky Mountain trench not very far from the area described by Dr Dreimanis and his student, found rocks of unusual provenance in till that had been derived from a valley on the opposite side of the trench. He had evidence from the till fabric here that the ice had been moving down the trench. He had to explain this as due to transport of these strange rocks by subglacial streams, across the ice or through the ice, from the opposite side, followed by incorporation with the ice-transported material. So that whenever we look at the products of glaciation we have to recognize that there may be water action there as well as normal glacier transport.

MeIER: Thank you. I want to stay pretty much with the problem of abrasion and plucking for the time being, we will get into regelation and so on in due course, and also subglacial hydrology.

Hallet: I would like to comment along the same line as Dr Mathews. One can look at eskers; these are deposited in subglacial tunnels, and are made up of sediments that are extensively water worked. Also one can look at a lot of material from tills and moraines and see evidence of periods of water working. One wonders how much energy is really spent in these subglacial streams in rounding rocks, and how many of the so-called glacial abrasion products are simply the result of this subglacial fluvial activity. This is a real problem when trying to estimate the energetics of the rock-to-rock friction at the base of the glacier. There is good reason to believe that a lot of energy is spent, and a lot of wear does occur, in these streams. For example, Robert Vivian reported up to $10 \mathrm{~cm}$ of fluvial erosion in about five years on quartzite, which is about the most resistant rock to mechanical erosion. So there are some very special attributes to these streams predominantly related to the kind of velocity that you have, the sediment content, and of course temperature. So I would simply like to warn people doing energy balances in estimating rock-to-rock friction, one should know the fact that much energy is probably being spent in these subglacial streams.

MeIer: And yet we do have the observations of Kamb, Engelhardt, Harris, Raymond, etc., and also those of Hodge that suggest that a very large percentage of the glacier interface is essentially not participating in an active hydrologic situation.

HALlet: I would like to point out that ice and entrained debris is continuously brought from adjacent areas into active conduits because of the relatively low pressure inside the conduits. It is likely, therefore, that subglacial fluvial activity affects a much larger volume of material than that anticipated from their limited aerial extent. 
Boulton: May I come back to something Dr Raymond said? If I understood him correctly when he was talking about statics, he said that we know the forces at the base of a glacier rather well. What a poor experimentalist wants to know when he is trying to generalize his results is how the drag is distributed over a realistic bed. How do the shear stress and normal pressure vary from place to place? If he can reassure me that we know, I shall follow him afterwards and write down every word he says. I suspect that we do not. I believe the two really important problems in sliding for which we need solutions are the problem of a twodimensional bed with finite slopes, and the problem of a three-dimensional bed.

RAYMOND: I do not want to suggest that we can write those things down precisely, but I think that one could know a lot about the force variations simply from the requirements of gross equilibrium. The longitudinal and normal averages can be determined well, although the fluctuations are less well determined. The fluctuations are important, of course, in for instance the net force on a bump sticking into the ice. Nevertheless, I think one can have a fairly good handle on these. In terms of how the ice responds by regelation and deformation, and the resulting rate of motion, we talk about order-of-magnitude differences between various experimental results and simple theoretical predictions. However, I do not think that we have order-of-magnitude differences in the forces.

Metcalf: I was just thinking about the controversy of the amount of plucking versus the amount of abrasion. One thing that might bear some importance in what Dr Boulton said about looking at tills and seeing all the large rocks but not really the fines formed, is that in my work on the Nisqually Glacier, I quite clearly showed that there was preferential erosion of the fines up-stream as compared to down-stream. Also Fahnestock's work on Emmons Glacier, also on Mount Rainier, shows the same thing; that you get the fines eroded. So in my opinion the fact that you do not see the fines there does not necessarily demonstrate the percentage of plucking versus abrasion, and in fact may be an artifact of a separate fluvial erosion process.

LLiBoutry: When the nature of the bedrock is not uniform, it would be interesting to observe the debris found under the glacier. The debris may come from the sides mainly because there is some transverse slope in the glacial valley and at the interface cavities often form. The pebbles can therefore move slowly towards the lower points, towards the centre of the valley. So we should not say that the debris falling on one side of the glacier all remains there as a lateral moraine. Some may move under the glacier and cover a great part of the ice/bedrock interface.

G. DE Q. RoBIN : Just one general point on plucking or grinding, with reference to the individual roches moutonnées. If grinding exceeds plucking, then we will not be able to pluck anything because it will all be ground away. In terms of the individual feature, there must be some sort of balance generalized over a large area, and where we have got roches moutonnées in a whole field, there must be a rough balance between the two processes, otherwise they would not be there.

J. W. GLEN: Where you have a typical glacial valley, with Riegeln and then perhaps an overdeepened basin, the rate of retreat of the step might give some indication of the rate of plucking, and the rate of lowering of the bottom may give some indication of abrasion. If the glacial geologists have a handle on how rapidly these processes have happened then this may give us some indication of this ratio.

Boulton: Processes of glacier erosion act extremely slowly. The reason they are volumetrically enormously important in producing material is that they occur over an immense area compared, say, with a stream, where there may locally be tremendous rates of erosion but in 
a very small area. The fact that processes are so slow means that it is difficult to use steadystate considerations. From what we know about the historical variations of glaciers, it seems safe to say that glacier regimes change frequently compared with the time that is probably required to develop a land form in stable equilibrium with the glacier. How can we estimate how long it takes to destroy the roughness of a bed by plucking, as Ian Whillans has suggested might occur, when the glacier is always changing in such a way as to produce new areas of plucking or abrasion? Steady-state considerations really are not very helpful here as the process acts slowly compared with the controls on the process.

Vivian: I would like to comment on these two processes abrasion and plucking, and the very important role of erosion by water under the glacier. Bernard Hallet spoke about the erosion of quartzite, but we have a lot of examples like that where water erosion is able to dig deep gorges and also to carry away all the material under the glacier. Water under a glacier is not only a problem of the water pressure affecting basal sliding, but is mainly a problem of direct erosion.

Meier: Yes, I think that is an important point, we must consider three processes, abrasion, plucking, and the transport or erosion by water.

Hallet : Incidentally, I have an observation in the Sierra Nevada in California, on what had been classically referred to as roches moutonnées on a mega scale. These are features that are about a hundred metres high. The lee side has classically been thought of as a quarried surface. If you look at that surface you can see that it is indeed due to water erosion. Large pot-holes correspond to what must have been subglacial cataracts or waterfalls that did most of the erosion. Sometimes you can still see the actual grinding stone that did some of the erosion. So in looking at roches moutonnées, we have to be very careful. The steep lee side could be due to jointing, but often we can see signs of water erosion. In the carbonate terrain where we have been working as I hope you saw yesterday, you can see extensive signs of erosion on the lee side of obstacles, which give rise to steep lee surfaces that superficially resemble quarried surfaces.

O. OrheIM: Many people have been talking today about using observations of deglaciated areas to examine glacier processes. The problem is that they are always looking at the effect of the action of the last stage of the glacier or the ice sheet. Now we have for example had talks during the week suggesting that erosion chiefly takes place during the main advance of glaciation, which may be very different from what we observe just after the glaciers have left an area. A particular point has to do with the effect of water. This can be very rapid and is certainly very important in the last stage of the glacier's life. We have examples of very large pot-holes in Norway (which we intend to demonstrate when we have our meeting there two years from now), which probably have been formed during the last few hundred years that the glaciers were present. So I think we have to be very careful about making geologic observations and saying this is how glaciers normally act.

R. M. Koerner: I would like to agree with Olav Orheim's comments. We must remember that the Wisconsin ice sheet retreated in such a manner that it is difficult to imagine where the energy came from to cause it to retreat at such a rate. It was a massive rate of retreat. There must have been a lot of water about and one cannot forget the effect of this water on the surrounding topography.

GoldthwAit: I would point to a contrast we see so often in mapping areas of past glaciation. If you have a massive limestone such as I was showing yesterday, and a shale next to it, which we have under Lake Erie, then the action of the ice on those two different lithologies is very very different. In the till overlying the shale you can see small chips of shale that have been 
partially detached, and pieces that have been completely detached, streaming off the outcrop into the till. In the shale I would say that plucking is $99^{\circ} \%$ of what is happening, and the plucked products are small chips simply because of the nature of the rock. On the other hand limestone is simply "sanded" and ground down to a powder; when it fails at joints it produces a few large blocks. Lithology is extremely important in what the glacier can do, so I think that both types of rock erosion have to be looked at.

R. BREPSON: I would like to point out that at the point where a slice of ice arrives on a bed rock, there is a concentration of stress on a singular point. This argument is based on the experiment with the Grenoble viscometer presented at this symposium, the results of which show a plastic adaptation to the bedrock just before the contact point: there is an accumulation of ice which arrives tangentially to the bed, attesting a maximum of the normal stress. After this maximum, I think that the normal pressure presents an attenuation and it is possible that a second maximum of stress exists, as computations tend to show. I think perhaps this remark has a certain significance.

MEIER: I wonder if there are any other comments that people would like to make about the actual physical processes involved in plucking or in any of these other mechanisms. We have had some rather interesting papers that talked about invasion of ice by plastic flow around rocks, we have had papers about hydrostatic plucking and so on. Are there comments on that subject?

Riley: As far as the clean ice/rock is concerned, the wear coefficients are one to two orders of magnitude less than that which one would obtain for the same rock in contact with itself. But, in getting that one to two orders-of-magnitude figure, it is interesting to describe to you what I observed, because I think this might throw some light on what we mean by plucking. The experimental set-up was a cylinder of ice over which was trapped a button in a helical path so that the rock would always see clean ice. At the end of that experiment there was a path about $2.5 \mathrm{~m}$ long, and along that path I could only detect under a microscope about I 5 particles of rock greater than $100 \mu \mathrm{m}$, along with innumerable finer particles far less than I $00 \mu \mathrm{m}$. At the same time I was monitoring friction at the interface, and on only one of those I 5 events was there any deviation from what I would normally consider to be the ploughing term. Now in arriving at my one to two orders of magnitude I have used just that one event. The other stuff just seemed to be lying there ready to be mopped up. One particle obviously put up a bit of a fight and it took some effort to get it out. How do we actually delineate what we mean by plucking? I find it a very wishy-washy term, I would like it tightened up.

Glen: One thing I am fairly certain of is that in most of the discussion we have heard about up till now this would not be regarded as "plucking". Most people use the term when considering the removal of large boulders. The process of abrasion itself has as you now suggest, differing terms including ones in which things may even get almost dissolved out of the rock, and ones in which the sand grains or the smaller sizes of particles are plucked out. But surely when we used the term "plucking" we were not talking about sand grains. So I think we are really thinking about something rather different.

KEMmis: I am somewhat alarmed at how the term "plucking" has been used here-apparently as if it could occur in only one way and under all glacial conditions. In the literature, and from papers presented at this conference, four mechanisms of "plucking" have been proposed, two of which are related to the processes of basal sliding. Dr Boulton's 1972 paper relating basal thermal regime to the occurrence of various glacial processes may be the key to understanding under what conditions different "plucking" processes will or can occur. Plucking during basal sliding by "enhanced basal creep" and "regelation" can only occur where the basal ice is at the pressure-melting point, if our basal-sliding theory is correct. Plucking by 
"enhanced basal creep" apparently occurs by the ice actually enveloping boulders, rocks, or pebbles on the glacier bed and carrying them away. Gunnar Østrem's slides illustrate this quite nicely. In Bernard Hallet's talk on regelation sliding over carbonate bedrock we saw thin sections of the carbonate precipitate in which small rock fragments were included. I would suggest that where glaciers "slide" over a fine-grained bed, regelation melt water may be capable of suspending individual clay-to-sand-size particles which may then be frozen into the glacier bed during regelation freezing-a second "plucking" mechanism. A third plucking mechanism is related to recent work by Drs Boulton and Sugden, who show that some glaciers may be composed of a sequence of thermal regime zones. This sequence of zones and appropriate subglacial hydrologic conditions enable this third process to occur. Basal melt water must be produced in an up-glacier zone of ice at the pressure-melting point. This melt water flows outward under the hydrostatic head to an outer zone where the ice is below the pressuremelting point. "Plucking" occurs as available basal debris is frozen in with the basal melt water at this "cold" outer zone. A final mechanism of "plucking"- on a very large scalewas illustrated by the "pop-out" features in Steve Moran's talk yesterday. His plucking mechanism also required a sequence of basal thermal-regime zones. In this case, melt-water flow is in the glacier-bed materials, not between the bed and the basal ice. This melt-water flow served to weaken the bed materials by locally increasing the pore pressures. Plucking occurred where: (I) the glacier was frozen to the bed because the frozen ice-bed contact enabled the ice to exert a tractive force on the bed materials; (2) pore pressures locally reduced the internal strength of the bed materials to a value less than the adhesive force between the ice and the bed; and (3) the glacier was undergoing compressive flow so that the materials could be transported or "plucked" from the bed. Thus we see that there are several different "plucking" processes, and that they occur in very different glacial settings. I think that this makes a discussion of the relative importance of abrasion to plucking quite silly, as obviously that relative importance will depend on the thermal regime zone or zones of the glacier.

Metcalf : I am very reticent to disagree with a man like Dr Glen, but I feel that I have to on this point about abrasion and different processes involved with abrasion. It seems to me that the abrasion of debris that we find in the literature of industrial grinding, is a process of attrition grinding: a rock-on-rock process just as Mr Riley described in his rock-on-rock wear experiments. I think we have to separate this from the process of plucking out small fragments, excuse the word, but I think that it is the best way that I can describe it at this time. For plucking itself, people may want to choose a different word for the changing length scale of particles removed, but $I$ think that abrasion clearly is attrition grinding of rock-on-rock.

GLEN : I am not sure I disagree. If you rub off something and if you look in a microscope and see that something has been pulled off, would you say that that was plucking? It was that that I was trying to distinguish.

MET CALF : I guess it is a question of whether it has been pulled off by ice or pulled off by rock.

GLEN: In that case we are in for difficulty of nomenclature are we not?

MeIER: We have had a non-abrasive session with many ideas plucked out. I would like to move to a slightly different subject now to make sure that we can cover some other interesting ideas which were left hanging in the technical sessions. We all realize, I believe, that glaciers flow over rough beds and the roughness is of some importance. I thought the papers by Lliboutry and Benoist, in regard to a shadowing function were extremely interesting. Perhaps we need to get some more information on what this roughness function really is, and to couple it to glacier models. So I would like to ask a question of our remote-sensing people. Is there a possibility that these shadowing functions or other functions which express the 
roughness of the glacier bed, can be determined remotely? I do remember an early paper by Professor Lliboutry in which he suggested going out with a flashlight on a dark, moonless night and shining the light obliquely on recently deglaciated terrain to obtain the shadowing function. Can we do this with radar or with some other technique?

Robin: One can get some sort of statistic out of this and we are looking at this type of problem, but I doubt if we can get it on the scale that you need for your flow properties at this stage. Whether or not we can come up with a good answer is, I think, still debatable. I would like to hear other opinions.

G. K. C. Clarke: I do not really know but I think that there may be certain problems in the usefulness of Berry's theory. One of the predictions of that theory is that the Hankel transform of the incoherent tail of a radar echo is related to the bed roughness spectrum. But the incoherent tail is rather short. So what we need is some really potent spectral-analysis technique such as the maximum-entropy method but based on the Hankel transform rather than the Fourier transform. Otherwise the main thing one will see is a truncation effect rather than the true spectrum.

Drewry: I think you have to try and expand on the problem at the radar-design end. At the moment we have radar systems which are specifically designed to look at large-scale characteristics of large ice masses. At frequencies between say 35 and $300 \mathrm{MHz}$ and operating through several kilometres of ice, we are integrating bed conditions over quite a large footprint. Resolved surfaces have, as a result, autocorrelation distances of tens to hundreds of metres and vertical variances of a few to tens of metres. Our scales are, therefore, far coarser than those necessary for modellers or investigators looking at small-scale bed effects such as pressure-melting. Unless you try statistical techniques which Garry Clarke mentioned, that is looking at individual pulses and pulse-shape modifications, you will probably not see very much more. In order to contribute useful real information for direct modelling of surfaces we need to obtain finer-scale radar definition by raising both frequency and power. But this is not easy.

K. C. Jezek: From what we have heard about radar so far, I see that people think of reflecting horizons or reflecting surfaces. I think the problem with using radio echo-sounding to define characteristics of the glacier bed is that you do not, at least from what we have seen at this meeting, have a reflecting horizon. You seem to have a gradient of material that is in the region where flow is occurring. Using radar to define that gradient is fairly difficult since there does not seem to be any specific boundary.

A. H. W. Woodruff: In response to Garry Clarke, I would like to say that proper polarization measurements of the return signal would help. The polarization is a function of the degree of coherence in the returned pulse, and you certainly get incoherence in the tail, and probably all the way through the returned wave envelope. If the returned wave function is resolved into two orthogonal polarization planes, then in each there is a coherent polarized component and an incoherent component which must be unpolarized. The incoherence arises from the reflection of the time-dependent rising and falling edges of the transmitted pulse from the many facets in the reflection zone, which occur both in the horizontal and vertical plane, and from their subsequent superimposition. It is possible, though it has not really been looked at in enough detail, that from the proportion of this unpolarized component one might well be able to say something about the vertical roughness of the bed or the distribution of boulder particles vertically in the bed.

C. R. Bentley: We are in the process of developing a digital recording radar system for use in the Antarctic which will be very sensitive. We hope that we will be able to look, among other things, in detail, at the nature of the scattering from the bottom surface. We will study 
extensively in a local area; we do not have to move very fast because we are not in an airplane, in fact we cannnot move very fast. We will take advantage of being a long time in one place to study, in as much detail as we can, one particular area. And, of course we hope that this will be useful in other places eventually.

RoBin: I think that there are two further comments. One is that we have already shown that you can view the difference between a flat subglacial lake surface and the rock surface. We can further improve our range resolution, which may help. The other point concerns changing the wavelengths and selecting other parameters to study particular problems. It would be fine if propagational conditions in the ice permitted use of all the wavelengths and frequencies that we wish to use for our various problems. However, not only equipment design but ice propagation conditions will limit what we can do.

Lliboutry: The shadowing function should be most interesting in the case of temperate glaciers which surge, or where there has been an ice fall, because there may be an instability for some types of shadowing function. We know that in general, temperate glaciers, completely temperate and always temperate, do not surge and do not fall. So what is happening in those few temperate glaciers which do surge, as some Icelandic glaciers? Or in the case of the Allalingletscher which fell? It would be interesting to examine the shadowing function of such glacier beds, to see if they are not different from the others.

MeIER: That is a good point. Are there any other possible ways by which we could infer the roughness of the beds of existing glaciers? I am really trying to get into this problem of how can we model glaciers, and it does not do us too much good to measure beds where there is no glacier, and then use that to calibrate our glaciers. I wish we could do the two together. Are there any other ideas on this?

Clarke: I wonder if Bernard Hallet and Dr Lliboutry would reflect on whether they really think that the spectrum of the bed now has an important role to play in sliding theories, since we now see the bed in such a mess.

Hallet: For some time we have been looking at rock surfaces exposed by the retreat of the glaciers. We did a bit of spectral analysis on different rock types and where different processes seem to dominate. The most spectacular result is that you can get a very very rough surface, and you just wonder how the glacier can slide over that. If you use a gross approximation of the sliding theory, taking fairly reasonable values from the basal shear stress, you get sliding velocities that are an order of a magnitude or two lower than that of the present glaciers, or the glaciers in the immediately surrounding area. These recently deglaciated rock surfaces are assumed to be very much the same in front of the glacier as they are below the glacier. The most problematical surfaces are the very rough ones for which the sliding theories are not suitable. For these surfaces, I wonder if it is really worth the effort to show just how rough they are and how the roughness is distributed through the wave spectrum.

LLiBoutry: The roughness of the bedrock when it has been washed proglacially, has perhaps very little to do with the real situation. This is displayed in the extent and the form of cavities. In the case of cavities, the spectral power density has nothing to do with the shadowing function, nor with the boundary condition. This is very simple to understand. Let us assume that the obstacles have very gentle slopes on the up-stream sides, and very steep ones on the down-stream sides. Now, the spectral power density is symmetrical. If the sliding law was dependent of this function, the friction would be the same for ice flowing in one direction or in the other, when obviously it cannot be the same. On the other hand in this case the shadowing function is not the same for both directions. 
Hallet: I might point out that for the profiles we have measured we first take the whole profile and analyse that spectrally. Then we try to account for the cavities. You know there is good contact between the ice and the rock where there are striae, and you know the area that has been skipped by basal ice. Where there was separation, you can draw in a cavity based on subglacial observations or you can use various kinds of extrapolation functions to give you a smooth curve. This gives you an idea of general effective roughness of the glacier sole, not that of the bed. Even when using that modified roughness, you obtain extremely low sliding velocities for what seem to be a reasonable basal shear stress. Physically, it is just too rough.

W. F. BudD: I would like to comment on the question raised by Hallet on the very rough beds. This is roughness on a large scale for which regelation, I think, is understood not to be important. So the important thing is the viscous drag or non-linear viscous drag. We find that it is just too hard to get high roughness to stop ice moving under those conditions if you have reasonably high shear stresses. The reason is that the yield stress of ice is time dependent. It is time dependent because recrystallization becomes important. For stresses in excess of two bars, you cannot support a load for any length of time; the ice will actually shear off. Now for big bumps the ice would not be held very long if that was the only mechanism, in fact it seems to me that you need some rock in the ice under these conditions to hold it there. So I think it is not a problem of too much roughness but the fact that rock is at least one way of holding the ice, once the stresses get high. If you have low stress like the one bar then it is not so critical.

F. Pessl: I was impressed with the smoothness and the relative steepness of the bedrock surface that you were working on. I wonder if much of the till has not perhaps been washed off, so that now you do not see the sediment that may have been on the glacier bed, nor that which may have occupied cavities or depressions in the bed and perhaps smoothed it out a bit. Also, your comment about the presence of moraine down-slope would suggest that sediment was available at one time to build the moraine. How much of the sediment that might have been on the rock has disappeared?

Hallet: In certain areas it is very difficult to estimate how much has been removed. You can go to areas that have been exposed in the last few years and if you see a fairly uniform distribution of debris despite the presence of pro-glacial streams, then one can be fairly sure that you have not lost very much from those areas. Now my feeling about the effect of debris on roughness is that it would just further roughen the bed. If we are already skipping the cavities, whether there is debris in the cavities or just "quarried bedrock" does not make much difference. The way I see it is: we are trying to make the bed as smooth as we legitimately can and we are ignoring additional roughness you can get from fragments that are coupled to the bed. Going back to the other point, I think it is very important that glacial geologists look for areas where they can establish that the material has not been removed post-glacially, and try to estimate from that something about a debris content in the ice.

Boulton: I think it is important that people should not go away from this symposium throwing their hands in the air about our lack of consensus. Garry Clarke said that our ideas of the glacier-bed interface are in a mess. I think it is rather that new work has demonstrated that our old generalizations are either no longer tenable, or that they are the wrong ones for current problems. We are thus attempting to evolve new generalizations, and it is merely that we have not yet agreed what they should be.

GLEN: I think I am right in saying that there are some glaciers in Antarctica flowing into the dry valleys in Victoria Land which are now flowing in the opposite direction from the direction in which the ice sheet flowed at an earlier stage. If we are right that a glacier tends to produce 
a sole that is nice and smooth and the bed has some roughness which, because of the shadowing function business, the glacier does not see, and if we were to suddenly take that glacier and make it go the other way, it should have an awful time. I wonder, has anybody looked at glaciers which are now local glaciers flowing in the opposite direction from the direction in which the ice sheet moulded the landscape to see how they are getting on? Do they slide? Perhaps of course we are too late and they have already turned the erosion round and are going the right way again, in which case the ice sheet should have some trouble when it comes back! Perhaps they are all cold glaciers and therefore it is irrelevant, but is there anywhere in the world where this sort of thing has happened?

Meier: I am sure the answer is yes, but!

Henoch: There are many examples of areas where ice has, at different times, flowed in diametrically opposed directions. The Columbia Icefield is one of them. The flow of ice from the Cordilleran Ice Sheet is known to have crossed the Continental Divide. Some of the Columbia Icefield glaciers must now be flowing in the opposite direction to the flow of the Cordilleran Ice Sheet over the area. However, scars indicating the flow of the Cordilleran Ice Sheet are only found high above the valleys near the last glaciation limits. I do not think we need envisage the flow of the Cordilleran Ice Sheet up the now-existing valleys. Ice of the thickness of this ice sheet could have been stationary in the lower part of its vertical profile where the slope of the floor of the valley was opposed to the direction of flow near the upper part of the profile. The floors of now-existing outlet glaciers have scars indicating the flow of ice down the valleys. Any scars indicating flow in the opposite direction have been obliterated if they were ever present.

Glen: Yes, I expect we are too late.

HALlet: I just have one further comment on the spectral analysis. We have not made serious attempts to cover the whole range of relevant frequencies, and so we have gone down to a size range where we think regelation is important for the velocities that were assumed. I might add that the kinds of velocities that I have been thinking about are in the order of tens of metres per year, and basal shear stresses are assumed to be around one bar. As we go through higher stresses certainly regelation does not appear as an important factor. You know the process is quite different, and the effective roughness of the bed seems to be very different.

MEIER: I think perhaps that in the future when our units are renegotiated the unit of pressure known as the bar will be defined as the average shear stress at the base of a glacier!

Clarke: One thing that struck me as interesting in the papers by Kamb and others and by Benoist was the measurement of what the exponent of the roughness spectrum was. There seems to be quite a large variation, certainly not indicating the kind of isotropic bed or the white spectrum that people wish for. I wonder if there is not some interesting latent information there about the history of the ice mass that once covered such terrain. Perhaps one could go around measuring roughness spectra on the Canadian shield and make interesting deductions about the ice sheet that covered it.

Lliboutry: I understood both studies lead to the same exponent.

ClaRkE: I thought it varied from around two up to more than three.

HALlet: We had three profiles that we did pretty carefully and our average turned out to be very similar to that of Benoist; surprisingly similar. We had 2.4 versus 2.36 I believe it was. But I hasten to add that in a paper pre-print Drs Melosh and Kamb showed that there was quite a variation from about two to four, and so they are on both sides of Nye's non- 
dimensional or white roughness. This is a tantalizing sort of result in that if you get some number that is pretty uniform, regardless of bedrock, one would say that maybe some subglacial process or combination of processes gives you that kind of morphology, more or less regardless of what you start with. That would be a very interesting result, but $I$ think that is a bit too simple.

Lliboutry: It was always measured in the same range of wavelengths?

Hallet: The wavelengths that I looked at were a little longer than those Benoist looked at, and I believe the ones that Melosh and Kamb studied were from about $5 \mathrm{~cm}$ to a couple of metres. So their scale is a little coarser too. But they always used the same scales and within that range of scales they observed that kind of variation from about two to about four.

CLARKE: That is very interesting. You can probably distinguish between a frozen bed and a melting bed.

RILEY: If we could just look at the heights of the roughness rather than a spectral analysis, how close would such heights be to a normal distribution?

HALleT: I frankly have not done that; until I saw the paper by Benoist and Lliboutry I never thought of doing that.

RILEY: Why I asked is that I am looking at very small roughness heights now, of the order of a millimetre or less, and, looking at the distributions of roughness on a rock surface after a rock-to-rock contact, they are anything but normal in distribution.

BuDD : I would like to comment on the question of the average stress at the base of the glacier, particularly in comparison with the shear stress of one bar. If you have one bar average, you do not need very big bumps to generate shear stresses well in excess of two bars. Under that shear stress, the recrystallization of the ice takes the orders of months to get to the stage where the tertiary and accelerating creep can set in. This means that we might have to take this into account in what controls the flow of the ice because we would have to get the recrystallization taking place as the ice moves up and over the bumps. You cannot leave the ice there for a very long time before that sort of thing sets in. After it does set in, with the passage of the glacier it moves to the next spot and it has got to be recrystallized again to go on to the next part. The big bumps are not enough to stop the ice.

MEIER: I would like to move on to that classic enigma of recrystallization. I know the paper by Souchez was very stimulating to me, showing another different mechanism. I believe Gordon Robin wanted to make a comment on this.

RoBın: I think that the work presented here in several directions has shown quite clearly that in temperate ice, pressure-melting starts when you first apply pressure, and the pressure determines temperature as Souchez showed by his chemical studies. With regelation around wires, a fine film of melt water was seen to shoot out ahead of the wire. You could see the melting within the ice mass ahead. That experiment, and Liz Morris's theoretical paper, all point to this process taking place. Water is produced in the ice. The temperature is determined by the pressure field, where the pressure is increasing. Meanwhile, as a further consequence, water is being squeezed out. Perhaps this idea has not been widely accepted, but the other problem of the flow properties of ice in which there is a proportion of free water present, needs attention. Some work has been done in this field in the laboratory. In addition the heat-pump idea suggests that after the pressure field is taken off, it will take some time for the ice to warm up again, and my rough calculations for basal glacier ice suggest how long this takes. Whether or not this is important perhaps remains to be seen in the light of further field observations and the laboratory work, but I think what is perhaps undoubted is that 
there is a considerable variation in the amount of free water in the ice near the glacier bed. This is going to produce an effect on flow equivalent to the roughness variation which we have been discussing in regard to ice and rock. So here is another variable which just makes the problem more complicated.

LliboutRY: As an average probably there is no change in the water content (otherwise in the ice at the front there would be plenty of liquid water), but at a small scale, there are surely big differences. We must question also if there are other processes in the creep of ice which must be taken into account. First the ice is bubbly and this gives a very strong delayed elasticity as observed in the experiment with "Penelope" by Mr Brepson (I did not have the time to explain this the other day). We must take into account the delayed elasticity of bubbly ice which gives a pressure on the up-stream side of a bump but not on the downstream side, because the expansion of bubbly ice happens a little after it has separated from the bed. Also transient creep makes the problem very difficult. Either we take a very simple model such as Glen's law to obtain rough estimates and then the fact that we do not know exactly the value of its parameters is unimportant, or we use the real complete law (which is no longer Glen's law) in a numerical computation.

T. J. Hughes: I would just like to reinforce the comments that Dr Robin and Professor Lliboutry made. The only parameters that have been quantitatively incorporated into a flow law are the external ones of temperature and stress. It was known for years that the creep properties of ice, from a qualitative point of view, are greatly changed by many factors: the density of ice, meaning the bubbliness; the purity of ice, both dissolved impurities and suspended particulate impurities; the grain size; the grain fabric; none of these have been quantitatively incorporated into any kind of a flow law even under steady state. When you throw in the added condition that you have near the glacier bed, transient creep, all we have is the work of Duval. Also, recrystallization relates creep-rate to the crystal fabric, but exactly how is completely unknown. If we are going to move away from the standard Glen-type creep flow law that has been applied in sliding theory and get into the new realm that Geoff Boulton suggested, where all of the conditions of purity and fabric that Tony Gow talked about with possibilities of shear bands, there has got to be an awful lot of work done on the creep flow of ice. The nature of the Glen body and Glen flow is very relevant, because ice especially near the bed is not a Glen body. It cannot possibly be, so to treat it in sliding theory as though it were, it is no wonder that you get sliding-rates that as Dr Hallet mentioned, are orders of magnitude lower than the sliding theories predict according to measured roughnesses. The flow law is totally unrealistic for the situation at the bed, and that in my opinion is where the major thrust of further work should be. Finally, at long last, we should quantitatively incorporate all of these internal properties of ice into a flow law.

MeIER: Perhaps I should ask Dr Glen how his body behaves near an ice/rock interface.

GLEN: No I think that is not what you want is it? You want somebody else's body! While agreeing completely with what Dr Hughes said about the importance of these other parameters I think one thing we can say is that a lot of them will not help reconcile the discrepancy which Dr Hughes has mentioned. Transient creep surely must make the flow faster under the application of the stress, not slower. Impurities usually make the flow faster, not slower. Fabric usually works in a direction to make the flow faster, not slower, and this will not help if the discrepancy is that the predicted flow is slower than comes out from the idealized model. This sounds the wrong way round for all these things, which does not encourage me in trying to insert some of them in the hope of getting better agreement. But perhaps I have got the sign of some of these wrong, I hope so. 
RoBin: I would like to point out that if the heat-pump concept was accepted, it is something that will make it slower if you have got a frozen bed, or frozen patches.

BudD: I think John Glen's description was completely back to front. To make the model work we need faster flow, very much faster in fact. We have a great deal of trouble of attaching plates to ice for shear experiments in excess of one bar in which to carry them through to tertiary creep. There is no way with a reduced stress on the plates that you can prevent the high shear if you have got little bumps or as rough as you make it. You produce stress concentration which can make the plates shear off, and the only way we have found to make proper samples that work is to have cylinders going through your moving partitions with a thinner amount of ice in the middle, so that your stresses in the deforming part are far less than what you have on your plate boundaries. Even then, once you go more than two bars, you quickly get into tertiary and accelerating creep.

Glen: Can we be clear on this? Do we want faster flow in order to account for the bed roughness we find?

Hallet: What I observed is this, if you take a look at the conventional theory, and I was using Nye's theory, you predict sliding velocities that are much lower than what you actually observe.

GLEN: Oh, that is the right way round for the additional terms I mentioned to help.

Lliboutry: Without cavitation?

GLEN: Oh yes, of course.

Hallet: I would like to point out that if you increase debris I think that is going to further slow it. If you increase solutes it is going to further slow it. So as Dr Glen suggested, some of these things which you can include would simply give you additional discrepancies.

GLEN: Yes, but some of them work. Transients, I think, work.

Hallet: That is right.

GLen: And dissolved impurities do not?

Hallet: Well solutes, if you incorporate them in the theory, will give you even slower predicted rates, which are already too small relative to those observed.

GLEN : On the creep side of it, these things will help. If they slow down regelation and increase the creep then this of course changes the critical obstacle size. It could do so quite dramatically, could it not?

Hallet: Yes, it changes, but it does not change it very dramatically.

Boulton: If you have deformable sediment beneath a glacier it would act as if it were resting on ball bearings. The reduction of sediment strength due to excess water production could act to speed up movement.

ENGELHARDT: I would remind you of the model of Kamb concerning what seems to reduce the sliding velocity considerably or stop it completely, from all our observations on Blue Glacier, which go back now for 25 years. On several parts of Blue Glacier we see no, or very little, sliding and we have formed the impression that rock friction in this active subsole drift is the most important part.

LliboutRy: We must not generalize in observations. I would like to bring here another very different observation in the case of some big Arctic glaciers like Kongsbreen in VestSpitsbergen which does not slide most of the year but in summer slides at several hundred 
metres to one kilometre a year. There is not a change in the basal quantity of drift during summer. There is a surge each summer, and in this case it might be explained by some subglacial water. It has nothing to do with drift.

RAYMOND: Well maybe this is going to change the direction a little bit, but we seem to be reaching the idea that water at the bottom of the glacier has a primary control on sliding. I noticed in the very interesting talk that Dr Iken gave yesterday that she suggested that the sliding velocity could increase dramatically at the onset of separation, but as cavities developed sliding-rate would slow down somewhat.

A. Iken: Yes, in the model the sliding velocity does slow down very much when the cavities have fully developed. The model does not, however, take into account bed roughness at a smaller scale. In reality small-scale roughness elements are present and when cavities have developed, contact is lost with some of these obstacles. Therefore the sliding velocity will remain higher than predicted by the model. The observations at Unteraargletscher do, however, suggest that even in the case of a real glacier the sliding velocity is much higher during the stage of cavity growth than at the time of maximum cavity volume.

Merer: Unfortunately our time is about to run out. I would like to ask if there are some comments that people would like to make in regard to the paper by Baranowski on drumlin formation.

GLEN: I think the important point about this is the suggestion that the drumlin is basically an erosional form, and that it is produced by erosion of the existing sediment. I think this is a suggestion which is obviously in an important area where a morphological feature has caused a lot of difficulty in explanation, and I think it would be a good thing to hear whether this meets with interest and is something which the glacial geologists think looks as if it is likely to be an acceptable idea or not.

Meier: I found the abstract very thought provoking. We must bring this meeting to a close.

Goldthwait: I have had the dilemma all my life of sometimes being called a glaciologist and not quite believing I was, and sometimes being called a glacial geologist, and sure that I was brought up that way. I think it would be too bad if this welding of the two aspects of glaciers were to be separated. I ask you to end the meeting by thanking at least four groups and organizations that have made this welding possible. I will mention first, of course, the organizing committee. They did a tremendous job: Bob Rogerson, Vic Prest, Stan Paterson, Bill Mathews, Fritz Koerner, Stephen Jones, Peter Johnson. Most especially of course Garry Clarke and Simon Ommanney did a marvellous job of planning. The second organization we owe great thanks to is the Royal Society of Canada. Getting the funding is ever necessary and has allowed wide attendance from many countries and laboratories. I think we did a noble job to haul John Fyles, spokesman for the Royal Society, down off the pipeline. Third, and most critical to our comfort is Carleton University. In spite of summer heat the meetings are comfortable, facilities for rest are excellent, and the meals close at hand were first class. Finally the International Glaciological Society in the persons of Madam Glaciology, Hilda Richardson, and our hard-working editor John Glen are to be congratulated for accepting this meeting back-to-back with its symposium and undertaking the huge job of editing and publication. 